\title{
Treatment of Non-neurogenic Overactive Bladder with OnabotulinumtoxinA: Systematic Review and Meta-analysis of Prospective, Randomized, Placebo-controlled Clinical Trials*
}

\section{Tratamento da bexiga hiperativa não neurogênica com toxina botulínica A: revisão sistemática e metanálise de ensaios clínicos prospectivos, randomizados e placebo-controlados*}

\author{
Raquel Martins Arruda ${ }^{1}$ Claudia Cristina Takano ${ }^{1}$ Manoel João Batista Castelo Girão ${ }^{1}$ \\ Jorge Milhem Haddad ${ }^{2}$ Gabriel Francisco Aleixo ${ }^{3}$ Rodrigo Aquino Castro ${ }^{1}$
}

1 Universidade Federal de São Paulo (UNIFESP), São Paulo, SP, Brazil

Address for correspondence Rodrigo de Aquino Castro, Universidade

2 Universidade de São Paulo (USP), São Paulo, SP, Brazil

${ }^{3}$ Universidade do Oeste Paulista, Presidente Prudente, SP, Brazil Federal de São Paulo, Rua Botucatu, 720, 04023-062, São Paulo, SP, Brazil (e-mail: rodrigo.castro@uol.com.br).

Rev Bras Ginecol Obstet 2018;40:225-231.

\begin{abstract}
Keywords

- overactive bladder

- systematic review

- botulinum toxin

- randomized controlled trials
\end{abstract}

Resumo
We performed a systematic review and meta-analysis of randomized placebo-controlled trials that studied non-neurogenic overactive bladder patients who were treated with 100 units of onabotulinumtoxinA or placebo. The primary purpose of our study was to evaluate the clinical effectiveness with regard to urinary urgency, urinary frequency, nocturia, and incontinence episodes. Our secondary purpose consisted of evaluating the adverse effects. Our initial search yielded 532 entries. Of these, seven studies met all the inclusion criteria (prospective, randomized, placebo-controlled studies, $\geq 3$ points on the Jadad scale) and were selected for analysis. For all primary endpoints, the toxin was more effective than placebo $(p<0.0001 ; 95 \%$ confidence interval [95Cl]), namely: urgency (mean difference $=-2.07 ; 95 \mathrm{Cl}=[-2.55-1.58]$ ), voiding frequency (mean difference $=$ $1.64 ; 95 \mathrm{Cl}=[-2.10-1.18]$ ), nocturia (mean difference $=-0.25 ; 95 \mathrm{Cl}=[-0.39-0.11]$ ) and incontinence episodes (mean difference $=-2.06 ; 95 \mathrm{Cl}=[-2.60-1.52]$ ). The need for intermittent catheterization and the occurrence of urinary tract infection (UTI) were more frequent in patients treated with onabotulinumtoxinA than in patients treated with placebo $(p<0.0001)$. Compared with placebo, onabotulinumtoxinA had significantly and clinically relevant reductions in overactive bladder symptoms and is associated with higher incidence of intermittent catheterization and UTI.

Realizou-se revisão sistemática e metanálise de estudos clínicos prospectivos, randomizados e placebo-controlados que comparavam a toxina botulínica ao placebo no tratamento da

This revision is part of the Project Series, Guidelines and Recommendations of FEBRASGO, elaborated by the FEBRASGO National Committee Specialized in Urogynecology and Vaginal Surgery.

received February 13, 2018 accepted

March 12, 2018
DOI https://doi.org/ $10.1055 / \mathrm{s}-0038-1642631$. ISSN 0100-7203.
Copyright $\odot 2018$ by Thieme Revinter Publicações Ltda, Rio de Janeiro, Brazil

License terms

(c) $(1) \$$ 


\author{
Palavras-chave \\ - bexiga hiperativa \\ - revisão \\ sistemática \\ - incontinência \\ urinária \\ - toxina botulínica \\ - estudos \\ randomizados \\ controlados
}

\begin{abstract}
bexiga hiperativa. O objetivo primário desta metanálise foi avaliar a eficácia da toxina botulínica em relação à urgência urinária, frequência miccional, noctúria e episódios de incontinência. $\mathrm{O}$ objetivo secundário foi avaliar os efeitos adversos. Selecionamos estudos que incluíram somente pacientes com bexiga hiperativa não-neurogênica tratada com 100 unidades de onabotulinum toxina A ou placebo (grupo controle). Foram encontrados 532 estudos após as buscas iniciais, dos quais sete apresentaram todos os critérios de inclusão (estudos prospectivos, randomizados, placebo-controlados, $\geq 3$ pontos na escala de Jadad) e fizeram parte desta análise. Para todos os objetivos primários a toxina foi mais eficaz do que o placebo, com $\mathrm{p}<0,0001$ e intervalo de confiança (IC) de 95\%: urgência (diferença média = $-2,07, I C=[-2,55 ;-1,58]$ ), freqüência miccional (diferença média $=-1,64, I C=[-2,10 ;-1,18]$ ), noctúria (diferença média $=-0,25, \mathrm{IC}=[-0,39 ;-0,11]$ ) e episódios de incontinência (diferença média $=-2,06, \quad \mathrm{IC}=[-2,60 ;-1,52])$. A necessidade de cateterização intermitente e a ocorrência de infecção urinária (ITU) foram mais frequentes no grupo toxina na comparação com o grupo placebo $(p<0,0001)$. A toxina botulínica promoveu melhora significativa dos sintomas de bexiga hiperativa na comparação com o placebo. Entretanto, está associada a uma maior incidência de cateterismo intermitente e infecção do trato urinário.
\end{abstract}

\section{Introduction}

The International Continence Society defines overactive bladder as a syndrome characterized by urinary urgency, with or without urgency urinary incontinence, usually accompanied by nocturia and an increase in urinary frequency, in the absence of infection, metabolic or local factors. ${ }^{1}$

Different population studies concluded that overactive bladder is highly prevalent both in males and females, with relevant negative impact on the patients' quality of life (social, physical, psychological, sexual, personal relationships, work, and domestic domains); moreover, it has a considerable financial impact on patients themselves and thus on the health care system. $^{2-5}$

Patients who do not satisfactorily respond to behavioral and/or pharmacological treatment are diagnosed with refractory overactive bladder. This group includes patients with contraindications and intolerable side effects to medication. ${ }^{6}$

While both the European Association of Urology (EAU) and the American Urological Association (AUA) recommend intravesical injection of botulinum toxin $A$ in refractory overactive bladder cases, a vast majority of articles discusses only neurogenic cases of this dysfunction. ${ }^{7,8}$

Our systematic review followed by meta-analysis included only non-neurogenic overactive bladder patients who were treated with 100 units of onabotulinumtoxinA.

\section{Methods}

Our study was registered in the PROSPERO database in 2016, under the reference number CRD42016035815.

Prospective randomized placebo-controlled studies featuring Jadad scale methodological quality $\geq 3$ were selected. ${ }^{9}$ The study populations should necessarily include patients aged 18 years or older with a diagnosis of non-neurogenic overactive bladder syndrome treated with 100 units of onabotulinumtoxinA, at least in one of the arms of the study.
Patients with mixed urinary incontinence and a clear prevalence of overactive bladder complaints were also included. Performance of urodynamic study was not considered a prerequisite for inclusion in our analysis, since overactive bladder diagnosis is clinically suspected and detrusor overactivity may or may not be present. The exclusion criteria comprised use of a dose other than 100 units of onabotulinum toxin $\mathrm{A}$, use of botulinum toxin other than onabotulinumtoxinA, neurogenic cases and literature or systematic reviews.

\section{Primary Outcomes}

The primary outcome of our study was to evaluate the clinical effectiveness with regard to the following variables: urgency (complaint of a sudden compelling desire to pass urine that is difficult to defer), ${ }^{1}$ urinary frequency (complaint by the patient who considers that he/she voids too often by day), ${ }^{1}$ nocturia (complaint that the individual has to wake up at night one or more times to void), ${ }^{1}$ and incontinence episodes (complaint of any involuntary leakage of urine). ${ }^{1}$

\section{Secondary Outcomes}

The secondary outcome was to evaluate all adverse effects reported in the studies included in the meta-analysis.

\section{Study Search and Selection}

We performed a search for randomized clinical trials (RCTs) in the following electronic databases: Cochrane Central Register of Controlled Trials (CENTRAL) and MEDLINE.

The MEDLINE search included the following terms: "overactive bladder," "detrusor overactivity," "bladder overactivity," "botulinum toxin," "onabotulinumtoxinA" and "botox."

Only studies in English were selected, and the search was done from the inception of the database, given that the use of botulinum toxin in the treatment of non-neurogenic overactive bladder is relatively recent. Two authors (R. M. A. and C. C. T.) independently reviewed all the abstracts and titles to select the papers that were relevant for review, later analyzing the full 
text of the selected studies to determine eligibility. The last online search was performed on June $20^{\text {th }}, 2015$. A spreadsheet for data collection was created to extract the data of interest in each article, which were then retyped in a single database to avoid loss of data or mistyping of any kind. Any disagreements were resolved by consulting a third author (R. A. C.). Outcomes verified in two articles or more were grouped for metaanalysis.

\section{Statistical Analysis}

We summarized binary outcomes based on the number of events using Peto odds ratio in situations with zero number of events in one of the groups, or the Mantel-Haenszel method in situations of a very low event rate. Furthermore, we summarized continuous outcomes (incontinence, urgency, frequency and nocturia) using the mean difference (MD), calculated by the inverse variance method. Precision of estimates appear as 95\% confidence intervals (95CIs).

Heterogeneity across studies was evaluated using Cochran Q statistic and Higgins I2. ${ }^{10}$ We quantified statistical heterogeneity using I2, informing its value together with the estimates. We considered I 2 elevated whenever it was higher than $60 \%$. However, a fixed-effect model was considered when a very small number of studies were included. ${ }^{10}$

In addition to the heterogeneity analyses described above, sensitivity analyses excluding one study at a time were performed to evaluate the influence of individual studies on the overall result. We used the RevMan 5.3 statistical package (Nordic Cochrane Center, Copenhagen, Denmark) to perform the analysis.

\section{Quality Assessment}

The quality of studies included in the analysis was independently assessed by two authors (R. M. A. and C. C. T.) using the Jadad scale for RCTs classification. ${ }^{9}$ Studies scoring $\geq 3$ were considered eligible for inclusion. Any disagreements were resolved by consulting a third author (R. A. C.).

The Jadad scale assesses the quality of published clinical trials based on methods relevant to random assignment, double blinding, and patient flow. There are seven items, but points may be deducted in the last two, which means that the range of possible scores is 0 (bad) to 5 (good). ${ }^{9}$ The bias risk was assessed by the use of a Cochrane collaboration tool. ${ }^{1}$

\section{Results}

\section{Description of Studies}

-Fig. 1 describes the flow chart for this review. Five hundred and thirty-two articles were retrieved after research on the Cochrane and Medline databases, using the keywords "overactive bladder" OR, "detrusor overactivity" OR "bladder overactivity" AND "botulinum toxin" OR "onabotulinumtoxinA" OR "botox."

Out of those, 333 articles were selected after reading the title and abstract, whereas 271 were excluded since they did not meet selection criteria. Therefore, 62 articles were considered eligible and read in full by two authors. After this initial reading, 53 articles were excluded for using onabotulinumtoxinB and/or for including patients with neurogenic overactive bladder. Eventually, 9 studies met all the inclusion criteria and were selected for this meta-analysis (-Fig. 1 and -Table 1)
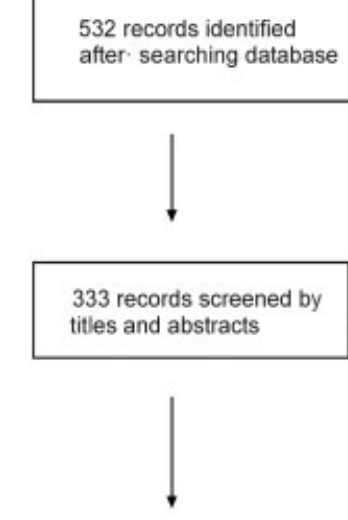

62 records were assessed for eligibility and were read and evaluated by the two authors 
Table 1 Articles included in the meta-analysis

\begin{tabular}{|l|l|l|l|l|}
\hline References & Study design & Jadad scale & N placebo/toxin & Weeks follow-up \\
\hline Chapple et al. $^{11}$ & Multicenter, randomized, double-blind & 5 & $271 / 277$ & 12 \\
\hline Denys et al. & & & 24 \\
\hline Dmochowski et al. $^{13}$ & Multicenter, randomized, double-blind & 5 & $29 / 70$ & 36 \\
\hline Dowson et al. $^{14}$ & Multicenter, randomized, double-blind & 5 & $43 / 268$ & 24 \\
\hline Flynn et al. $^{15}$ & Single-center, randomized, double-blind & 5 & $11 / 10$ & 6 \\
\hline Nitti et al. & Single-center, randomized, double-blind & 5 & $7 / 15$ & 36 \\
\hline Rovner et al. & Multicenter, randomized, double-blind & 5 & $44 / 54$ & 36 \\
\hline
\end{tabular}

Two studies could be included for analysis of urinary urgency, urinary frequency, nocturia, and incontinence episodes. There was no evidence of heterogeneity among the articles, except for urinary incontinence. However, because the number of articles is very small, the fixed-effect model was considered.

It can be observed in - Fig. 2 that there was significant reduction in urinary urgency episodes in the toxin group (experimental group) in comparison with the placebo group (control group) $\quad(\mathrm{MD}=-2.07, \quad 95 \mathrm{CI}=[-2.55 ; \quad-1.58]$; $p<0.0001$ ).

-Fig. 3 shows that there was significant reduction in urinary frequency in the toxin group (experimental group) when compared with the placebo group (control group) $(\mathrm{MD}=-1.64,95 \mathrm{CI}=[-2.10 ;-1.18] ; p<0.0001)$.

A similar result was observed in analyzing nocturia episodes (-Fig. 4). There was significant reduction in nocturia in the toxin group (experimental group) in relation to the placebo group (control group) $(\mathrm{MD}=-0.25,95 \mathrm{CI}=[-0.39 ;-0.11]$; $p<0.0001)$.

In - Fig. 5 we further confirmed that there was significant reduction in the number of urinary incontinence episodes in the toxin group (experimental group) in relation to the placebo group (control group) $(\mathrm{MD}=-2.06,95 \mathrm{CI}=[-2.60 ;-1.52]$; $p<0.0001)$.

\section{Secondary Purposes}

\section{Adverse Effects of Catheterization}

For analysis of vesical catheterization occurrence, it was possible to include five studies. According to the data (-Fig. 6), it is possible to verify that the need for catheterization was significantly higher in the toxin group (experimental

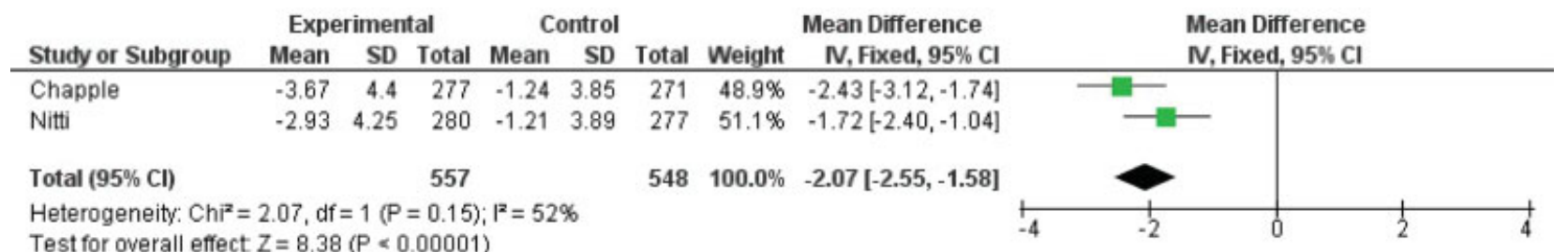

Fig. 2 Forest plot of change in urgency after onabotulinumtoxinA (experimental) and placebo (control) injections.

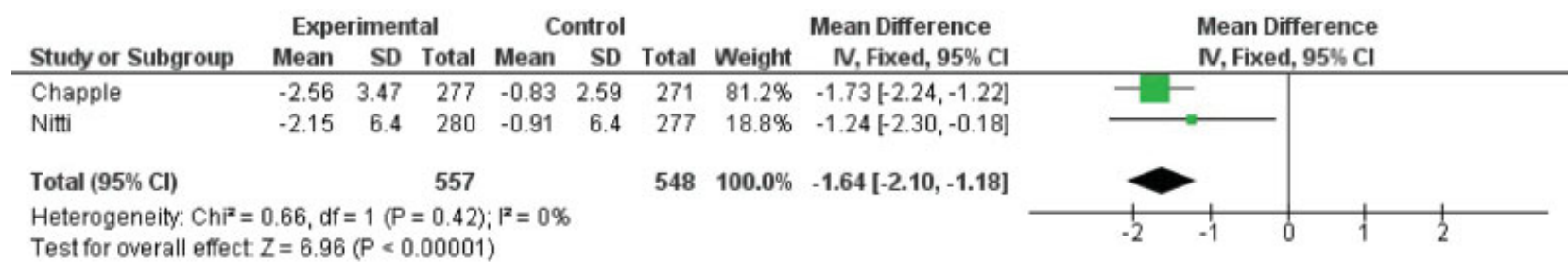

Fig. 3 Forest plot of change in frequency after onabotulinumtoxinA (experimental) and placebo (control) injections.

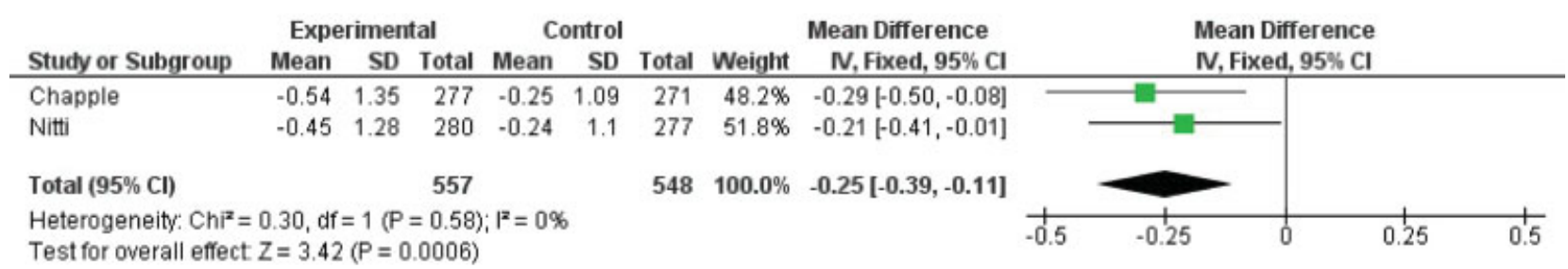

Fig. 4 Forest plot of change in nocturia episodes after onabotulinumtoxinA (experimental) and placebo (control) injections. 


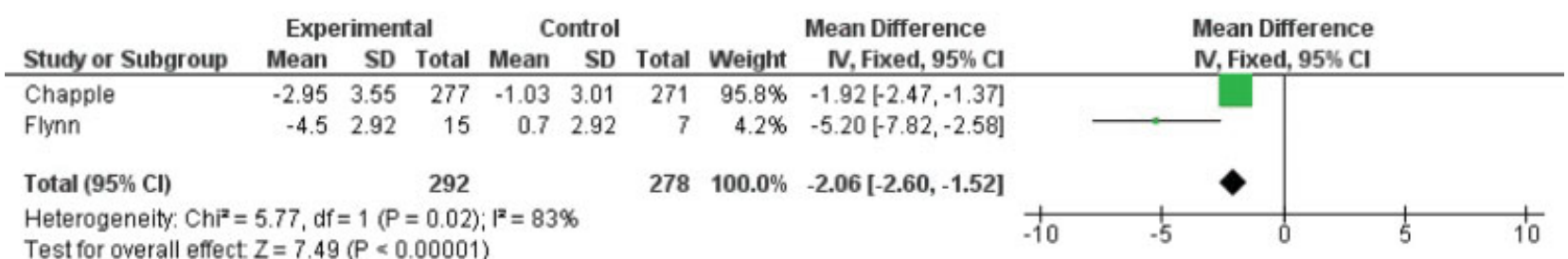

Fig. 5 Forest plot of change in urinary incontinence episodes after onabotulinumtoxinA (experimental) and placebo (control) injections.

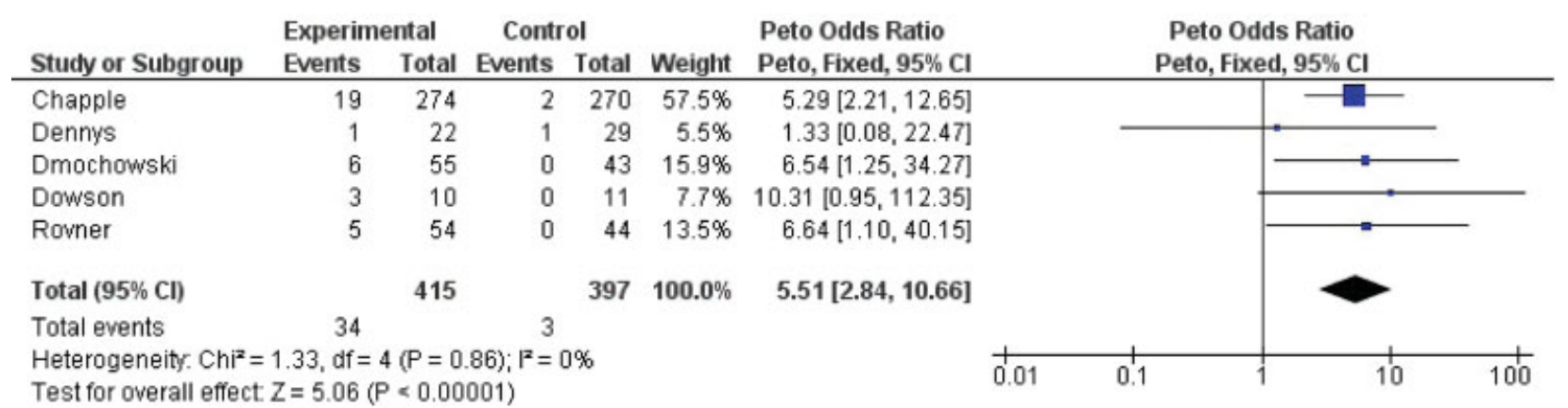

Fig. 6 Forest plot of change of pulmonary vascular resistance-related catheterization after 100 units of onabotulinumtoxinA (experimental) and placebo (control) injections.

\begin{tabular}{|c|c|c|c|c|c|c|c|c|c|c|}
\hline Study or Subgroup & \multicolumn{2}{|c|}{ Experimental } & \multicolumn{2}{|c|}{ Control } & Weight & $\begin{array}{l}\text { Peto Odds Ratio } \\
\text { Peto, Fixed, } 95 \% \mathrm{Cl}\end{array}$ & \multicolumn{3}{|c|}{$\begin{array}{c}\text { Peto Odds Ratio } \\
\text { Peto, Fixed, } 95 \% \mathrm{Cl}\end{array}$} & \\
\hline Chapple & 66 & 274 & 26 & 270 & $75.1 \%$ & $2.79[1.78,4.37]$ & & & & \\
\hline Dennys & 0 & 22 & 2 & 29 & $1.9 \%$ & $0.17[0.01,2.81]$ & & & 一 & \\
\hline Dmochowski & 20 & 55 & 7 & 43 & $19.1 \%$ & $2.71[1.11,6.58]$ & & & $\longrightarrow-$ & \\
\hline Dowson & 4 & 10 & 1 & 11 & $3.9 \%$ & $5.07[0.71,36.05]$ & & & & \\
\hline Total $(95 \% \mathrm{Cl})$ & & 361 & & 353 & $100.0 \%$ & $2.69[1.83,3.97]$ & & & & \\
\hline Total events & 90 & & 36 & & & & & & & \\
\hline $\begin{array}{l}\text { Heterogeneity. Chi }{ }^{2} \\
\text { Test for overall effec }\end{array}$ & $\begin{array}{l}4.15, d f= \\
Z=5.00\end{array}$ & $\begin{array}{l}(P=0 \\
<0.00\end{array}$ & $\begin{array}{l}25) ; 1^{2}=? \\
001)\end{array}$ & $28 \%$ & & & 0.005 & 0.1 & 10 & 200 \\
\hline
\end{tabular}

Fig. 7 Forest plot of change of urinary tract infection after 100 units of onabotulinumtoxinA (experimental) and placebo (control) injections.

group) when compared with the placebo group (control group), with no heterogeneity in this analysis.

In - Fig. 7 we present the forest plot graph for the data referring to urinary tract infection occurrence. We note in the plot forest graph that the Peto odds ratio meta-analytical value $(\mathrm{OR}=2.69$, IC $(95 \%)=[1.83 ; 3.97] ; p$ value $<0.0001)$ is located fully to the right of the vertical line. Such result demonstrates higher probability of urinary infection in the toxin group (experimental) when compared with the placebo group (control). Homogeneity among studies was confirmed by $\mathrm{Q}$ (Chi) in the Cochran test ( $\mathrm{p}$ value $=0.25$ ).

Regarding the quality of life evaluation, it was not possible to perform the meta-analysis, since the authors used different questionnaires, which made it impossible to evaluate this item.

\section{Discussion}

Our results demonstrated that the onabotulinumtoxinA had greater efficiency when compared with the placebo in relation to the all the symptoms analyzed (urinary frequency, nocturia, and urinary incontinence episodes). Such results are also in agreement with other systematic reviews and meta-analyses in respect to the subject. ${ }^{18,19}$
There was significant reduction in the number of urinary urgency episodes in the group treated with toxin in comparison with the placebo group. However, none of the studies evaluated urgency intensity, probably because it is a subjective symptom, and it is very difficult to be characterized.

The last Cochrane review (2011) ${ }^{19}$ on this topic included 19 studies, mostly with neurogenic patients. In our study, we were interested in demonstrating the efficacy of onabotulinumtoxinA in the treatment of non-neurogenic overactive bladder, which is usually followed by the gynecologist.

We chose to include only articles in which the toxin used was onabotulinumtoxinA because it is the toxin most frequently indicated in Brazil, and it is available to treat overactive bladder in both private and public health services.

Although most studies included analyzed the patients' quality of life, unfortunately it was not possible to perform a systematic review of this variable given that the authors used different tools for this evaluation. Nevertheless, different studies have concluded that botulinum toxin significantly improves patient symptoms and quality of life. ${ }^{11,20}$

In the articles included in our study, the only side effects significantly higher in the toxin group in comparison with the placebo were urinary tract infection and urinary retention. Such 
side effects were both more frequent in the 100 units dose. Furthermore, other possible side effects are dry mouth, hematuria, respiratory depression, and general muscular weakness. ${ }^{21}$

Urinary retention was the main complication reported in the studies. According to the literature data, its incidence ranges from $0-72 \%$, depending on the toxin dose used and the definition of urinary retention with or without need for catheterization (which is extremely variable among the authors). ${ }^{19,20}$ Most articles included in this meta-analysis considered as urinary retention the presence of post-urination residue $\geq 200 \mathrm{~mL} .^{11-13,17}$

The need for intermittent catheterization at the 100 units dose, which is the most frequently used dosage in nonneurogenic cases, ranged from $6.9^{11}-30 \%{ }^{14}$

It should be noted, however, that the indication of catheterization was varied among the studies. The lowest rate was in Chapple et al, ${ }^{11}$ which only indicated it in asymptomatic cases if post-urination residue was $\geq 350 \mathrm{~mL}$. In turn, Brubaker et al $(2008)^{21}$ indicated intermittent catheterization in cases with post-urination residue $>200 \mathrm{~mL}$ after 4 weeks from the injection, regardless of the symptoms. Such differences between the definitions for urinary retention and the need for catheterization render comparison among studies difficult. In addition, possible clinical consequences of asymptomatic urinary retention are not clear. Regardless, such retention is transitory and dose-dependent. ${ }^{11,20,22}$

The primary strength of this systematic review was to only include prospective, randomized, placebo-controlled articles featuring Jadad scale methodological quality $\geq$ than 3. ${ }^{9}$ The fact that we have only included patients treated with 100 units of onabotulinumtoxinA and non-neurogenic cases also contributed to facilitate the interpretation of results.

The limitations refer mainly to the differences between injection application techniques, the follow-up time, and the evaluation of quality of life, which undoubtedly renders greater generalization of results.

\section{Conclusion}

In comparison with the placebo, onabotulinumtoxinA promotes significant improvement of urinary urgency, urinary frequency, nocturia, and incontinence symptoms. There is higher incidence of urinary retention and urinary tract infection among patients in the toxin group in relation with the placebo group. It was not possible to evaluate the effects on quality of life. This systematic review is endorsed by the Urogynecology Committee of the Federação das Associações Brasileiras de Ginecologia e Obstetrícia (Brazilian Federation of the Societies of Gynecology and Obstetrics, [FEBRASGO, in the Portuguese acronym]) and suggests that the dose of 100 units of onabotulinumtoxinA is effective in the treatment of nonneurogenic refractory overactive bladder.

\section{References}

1 Haylen BT, de Ridder D, Freeman RM, et al; International Urogynecological Association; International Continence Society. An
International Urogynecological Association (IUGA)/International Continence Society (ICS) joint report on the terminology for female pelvic floor dysfunction. Neurourol Urodyn 2010;29 (01):4-20. Doi: 10.1002/nau.20798

2 Milsom I, Abrams P, Cardozo L, Roberts RG, Thüroff J, Wein AJ. How widespread are the symptoms of an overactive bladder and how are they managed? A population-based prevalence study. BJU Int 2001;87(09):760-766. Doi: 10.1046/j.1464-410x.2001.02228.x

3 Irwin DE, Milsom I, Hunskaar S, et al. Population-based survey of urinary incontinence, overactive bladder, and other lower urinary tract symptoms in five countries: results of the EPIC study. Eur Urol 2006;50(06):1306-1314, discussion 1314-1315. Doi: $10.1016 /$ j.eururo.2006.09.019

4 Coyne KS, Wein A, Nicholson S, Kvasz M, Chen CI, Milsom I. Comorbidities and personal burden of urgency urinary incontinence: a systematic review. Int J Clin Pract 2013;67(10):1015-1033. Doi: 10.1111/ijcp.12164

5 Onukwugha E, Zuckerman IH, McNally D, Coyne KS, Vats V, Mullins CD. The total economic burden of overactive bladder in the United States: a disease-specific approach. Am J Manag Care 2009;15(4, Suppl)S90-S97

6 Willis-Gray MG, Dieter AA, Geller EJ. Evaluation and management of overactive bladder: strategies for optimizing care. Res Rep Urol 2016;8:113-122. Doi: 10.2147/RRU.S93636

7 Gormley EA, Lightner DJ, Faraday M, Vasavada SP; American Urological Association; Society of Urodynamics, Female Pelvic Medicine. Diagnosis and treatment of overactive bladder (nonneurogenic) in adults: AUA/SUFU guideline amendment. J Urol 2015;193(05):1572-1580. Doi: 10.1016/j.juro.2015.01.087

8 Lucas MG, Bosch RJ, Burkhard FC, et al; European Association of Urology. EAU guidelines on surgical treatment of urinary incontinence. Eur Urol 2012;62(06):1118-1129. Doi: 10.1016/ j.eururo.2012.09.023

9 Jadad AR, Moore RA, Carroll D, et al. Assessing the quality of reports of randomized clinical trials: is blinding necessary? Control Clin Trials 1996;17(01):1-12. Doi: 10.1016/0197-2456 (95)00134-4

10 Higgins JPT, Thompson SG, Deeks JJ, Altman DG. Measuring inconsistency in meta-analyses. BMJ 2003;327(7414):557-560. Doi: $10.1136 /$ bmj.327.7414.557

11 Chapple C, Sievert KD, MacDiarmid S, et al. OnabotulinumtoxinA $100 \mathrm{U}$ significantly improves all idiopathic overactive bladder symptoms and quality of life in patients with overactive bladder and urinary incontinence: a randomised, double-blind, placebocontrolled trial. Eur Urol 2013;64(02):249-256. Doi: 10.1016/j. eururo.2013.04.001

12 Denys P, Le Normand L, Ghout I, et al; VESITOX study group in France. Efficacy and safety of low doses of onabotulinumtoxinA for the treatment of refractory idiopathic overactive bladder: a multicentre, double-blind, randomised, placebo-controlled doseranging study. Eur Urol 2012;61(03):520-529. Doi: 10.1016/j. eururo.2011.10.028

13 Dmochowski R, Chapple C, Nitti VW, et al. Efficacy and safety of onabotulinumtoxinA for idiopathic overactive bladder: a doubleblind, placebo controlled, randomized, dose ranging trial. J Urol 2010;184(06):2416-2422. Doi: 10.1016/j.juro.2010.08.021

14 Dowson C, Sahai A, Watkins J, Dasgupta P, Khan MS. The safety and efficacy of botulinum toxin-A in the management of bladder oversensitivity: a randomised double-blind placebo-controlled trial. Int J Clin Pract 2011;65(06):698-704. Doi: 10.1111/j.17421241.2011.02663.x

15 Flynn MK, Amundsen CL, Perevich M, Liu F, Webster GD. Outcome of a randomized, double-blind, placebo controlled trial of botulinum A toxin for refractory overactive bladder. J Urol 2009;181 (06):2608-2615. Doi: 10.1016/j.juro.2009.01.117

16 Nitti VW, Dmochowski R, Herschorn S, et al; EMBARK Study Group. OnabotulinumtoxinA for the treatment of patients with overactive bladder and urinary incontinence: results of a phase 3 , randomized, 
placebo controlled trial. J Urol 2013;189(06):2186-2193. Doi: 10.1016/j.juro.2012.12.022

17 Rovner E, Kennelly M, Schulte-Baukloh H, Zhou J, Haag-Molkenteller C, Dasgupta P. Urodynamic results and clinical outcomes with intradetrusor injections of onabotulinumtoxinA in a randomized, placebo-controlled dose-finding study in idiopathic overactive bladder. Neurourol Urodyn 2011;30(04):556-562. Doi: 10.1002/nau.21021

18 Cui Y, Wang L, Liu L, et al. Botulinum toxin-A injections for idiopathic overactive bladder: a systematic review and metaanalysis. Urol Int 2013;91(04):429-438. Doi: 10.1159/000351037

19 Duthie JB, Vincent M, Herbison GP, Wilson DI, Wilson D. Botulinum toxin injections for adults with overactive bladder syn- drome. Cochrane Database Syst Rev 2011;(12):CD005493. Doi: 10.1002/14651858.CD005493.pub3

20 Rechberger T, Miotła P, Skorupski P, Wróbel A, Tomaszewski J. [The quality of life of patients with overactive bladder after local injections of botulinum toxin A-a preliminary report]. Ginekol Pol 2010;81(01):24-30

21 Brubaker L, Richter HE, Visco A, et al; Pelvic Floor Disorders Network. Refractory idiopathic urge urinary incontinence and botulinum A injection. J Urol 2008;180(01):217-222. Doi: 10.1016/j.juro.2008.03.028

22 Marinkovic SP, Rovner ES, Moldwin RM, Stanton SL, Gillen LM, Marinkovic CM. The management of overactive bladder syndrome. BMJ 2012;344:e2365. Doi: 10.1136/bmj.e2365 